19,10

\title{
Механизмы переноса тепла и температурная зависимость теплового сопротивления кристаллов $\mathrm{CaLa}_{2} \mathrm{~S}_{4}$
}

\author{
() С.М. Лугуев ${ }^{1}$, Н.В. Лугуева ${ }^{1}$, Т.С. Лугуев ${ }^{1,2}$ \\ ${ }^{1}$ Институт фризики им. Х.И. Амирханова ДагНЦ РАН, \\ Махачкала, Россия \\ ${ }^{2}$ Дагестанский государственный университет, \\ Махачкала, Россия \\ E-mail: luguev.if@mail.ru
}

Поступила в Редакцию 4 июня 2019 г.

В окончательной редакции 14 августа 2019 г.

Принята к публикации 14 августа 2019 г.

Представлены результаты исследования температурной зависимости теплового сопротивления кристаллов $\mathrm{CaLa}_{2} \mathrm{~S}_{4}$ в диапазоне температур $80-450 \mathrm{~K}$ по данным измерения их коэффициента теплопроводности. Установлены механизмы теплопереноса в образцах, имеющих различную технологическую предысторию. Выявлены причины, определяющие величину и особенности температурной зависимости теплового сопротивления кристаллов $\mathrm{CaLa}_{2} \mathrm{~S}_{4}$ в области и выше температуры Дебая.

Ключевые слова: теплопроводность, тепловое сопротивление, фононы, дефекты, фотоны.

DOI: 10.21883/FTT.2020.01.48758.504

\section{1. Введение}

Соединение $\mathrm{CaLa}_{2} \mathrm{~S}_{4}$ имеет кубическую структуру типа фосфида тория $\left(\mathrm{Th}_{3} \mathrm{P}_{4}\right)$, высокую температуру плавления $\left(T_{m}=2300 \mathrm{~K}\right)$, большую ширину запрещенной зоны $(E=2.7 \mathrm{eV})$ и широкую полосу оптической прозрачности $(0.4-18 \mu \mathrm{m})$, что предопределяет его привлекательность для применения в оптических устройствах инфракрасного диапазона [1-5].

Решение вопросов практического применения материала требует всестороннего изучения свойств, определяющих его функциональные возможности. Свойства материала в существенной мере зависят от структурных особенностей, связанных с его технологической предысторией. Во многих случаях использование поликристаллических материалов, полученных методом горячего прессования, может оказаться более предпочтительным, чем монокристаллов, полученных кристаллизацией из расплава. Для упрощения далее в тексте поликристаллические образцы, полученные методом горячего прессования, будем называть керамиками, а образцы, полученные из расплава, - кристаллами. Теплофизические свойства, в том числе и теплопроводность, являются параметрами, данные о которых требуются, как для оптимизации процессов получения совершенных материалов, так и для решения конструкторских задач при техническом применении.

Литературные данные о коэффициенте теплопроводности $(\kappa) \mathrm{CaLa}_{2} \mathrm{~S}_{4}$ обобщены в работе [6]. Они относятся, в основном, к температурам вблизи $300 \mathrm{~K}$, за исключением данных из [7], где приведены результаты для области температур 350-828 К. Эти данные характеризуют поликристаллы, полученные горячим прессованием. В ряде работ [8-12] приводятся данные о теп- лофизических свойствах образцов $\mathrm{CaLa}_{2} \mathrm{~S}_{4}$, полученных кристаллизацией из расплава, но детального рассмотрения механизмов, определяющих перенос в них тепла нет. Это относится и к работе [6], в которой представлены данные измерений коэффициента теплопроводности керамики в области температур 80-400 К и кристалла в диапазоне температур 80-450 K.

Целью настоящей работы является исследование механизмов теплопереноса в твердых образцах $\mathrm{CaLa}_{2} \mathrm{~S}_{4}$, имеющих различную технологическую предысторию (кристаллизация из расплава или горячее прессование исходного порошка), выяснение причин, определяющих величину и температурные зависимости теплопроводности и теплового сопротивления, выявление роли фононных мод (акустических и оптических) в теплопереносе.

\section{2. Методика эксперимента}

Исследования проведены на образцах $\mathrm{CaLa}_{2} \mathrm{~S}_{4}$, полученных в АО „НПО Государственный оптический институт им. С.И. Вавилова“ (Санкт-Петербург) в соответствии с методиками: [13] — керамика, [14] кристаллы. Соединение $\mathrm{CaLa}_{2} \mathrm{~S}_{4}$ в виде порошка было получено сульфидированием кислородсодержащих соединений лантана и кальция $\left(\mathrm{CaSO}_{4}\right.$ и $\left.\mathrm{La}_{2}\left(\mathrm{SO}_{4}\right)_{3}\right)$ [14]. Для получения керамики проводилось прессование полученного порошка $\mathrm{CaLa}_{2} \mathrm{~S}_{4}$ в вакуумной пресс-печи при температуре $1600 \mathrm{~K}$ и удельном давлении $200 \mathrm{MPa}$. Время выдержки под давлением - $40 \mathrm{~min}$. Полученные заготовки затем отжигались при температуре $1270 \mathrm{~K}$ в течение $2 \mathrm{~h}$ в потоке сульфидирующих газов $\left(\mathrm{H}_{2} \mathrm{~S}\right.$ и $\left.\mathrm{CS}_{2}\right)$. В результате были получены плотные высокопрозрачные поликристаллические образцы со средним размером зе- 
рен 4-6 $\mu$ т и плотностью равной $\rho=4.55 \mathrm{~g} / \mathrm{cm}^{3}$, не содержащие трещины и поры. Кристаллы были получены плавлением исходного порошка $\mathrm{CaLa}_{2} \mathrm{~S}_{4}$ и последующим отжигом в парах серы при температурах $T>1900 \mathrm{~K}$. Рентгенофазовый анализ показал, что образцы, полученные как горячим прессованием, так и плавлением исходного порошка, имеют кубическую кристаллическую структуру типа фосфида тория.

Измерения коэффициента теплопроводности выполнены абсолютным методом при стационарном и квазистационарном тепловых режимах на той же установке, что и в работе [6]. Эта методика определения коэффициента теплопроводности аттестована в ФГУП „Стандартинформ“ в качестве методики ГСССД [15], где приведены принципиальная схема прибора, методика проведения измерений и расчетные формулы. Для получения данных о температурной зависимости коэффициента теплопроводности прибор последовательно погружался в среды, создающие стационарный тепловой режим в приборе (жидкий азот, смесь углекислоты с ацетоном или этиловым спиртом, лед с $\mathrm{CaCl}_{2}$ и $\mathrm{NaCl}$, тающий лед, кипящая вода). В каждой среде измерения проводились при различных мощностях градиентной печи, что позволяло получить на кривой $\kappa(T)$ непрерывный ряд точек с небольшими разрывами. Режимные нагреватели, находящиеся внутри прибора, водяной термостат и наружная печь, в которые помещается прибор при температурах выше комнатной температуры и температуры кипения воды, создают в приборе квазистационарные условия. При этом в измерительной ячейке температурные изменения не превышали $0.5 \mathrm{~K} / \mathrm{h}$, и температурные режимы существенно не отличались от условий стационарного режима, создаваемого термостатирующими средами. Средняя квадратическая погрешность измерений с учетом погрешностей: определения мощности градиентной печи; излучений с боковых поверхностей нагревателя и образцов; оттока или подвода тепла по проводам; определения геометрических размеров образцов и температуры термопарами не превышают $2-4 \%$ в зависимости от области температур.

\section{3. Результаты и их анализ}

Результаты экспериментального исследования коэффициента теплопроводности $\mathrm{CaLa}_{2} \mathrm{~S}_{4}$ представлены на рис. 1. Диапазон измерения теплопроводности керамик в настоящем исследовании расширен до $450 \mathrm{~K}$. Полученные данные совпадают в пределах погрешности измерения со значениями $\kappa$, приведенными в [6]. По данным эксперимента температурные зависимости теплопроводности кристаллов и керамики $\mathrm{CaLa}_{2} \mathrm{~S}_{4}$ имеют вид, характерный для переноса тепла в основном колебаниями кристаллической решетки (фононами). Теплопроводность керамики, несмотря на то, что она имеет плотность, равную плотности плавленых образцов, несколько ниже, чем для кристалла. Наблюдающиеся различия данных для керамики и кристалла становятся более

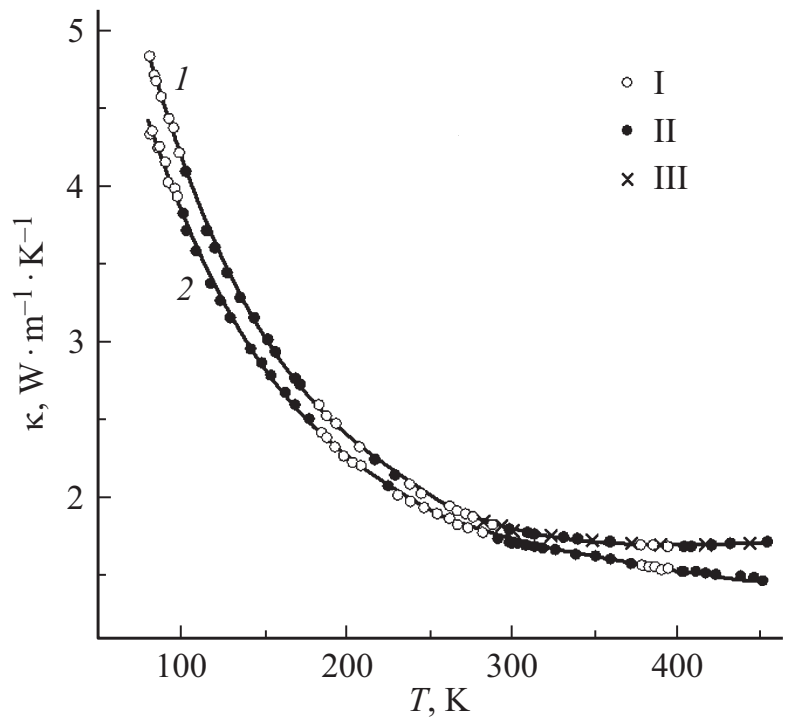

Рис. 1. Температурные зависимости коэффициента теплопроводности $\kappa$ образцов $\mathrm{CaLa}_{2} \mathrm{~S}_{4}$ различной технологической предыстории: 1 - образцы, полученные кристаллизацией из расплава; 2 - образцы, полученные методом горячего прессования. I - измерения в стационарных условиях; II измерения в квазистационарных условиях; III - данные из работы [10].

существенными в высокотемпературной области измерений: если разница в величине $\kappa$ кристалла и керамики при $300 \mathrm{~K}$ составляет не более $4 \%$, то при повышении температуры она возрастает до $16 \%$ при $450 \mathrm{~K}$.

Оценка роли механизмов, ограничивающих теплопроводность кристаллической решетки, может быть проведена в рамках модели Дебая [16] по длине свободного пробега фононов:

$$
l=\frac{3 \kappa}{C_{V} v},
$$

где $C_{V}$ - теплоемкость единицы объема; $v-$ средняя скорость распространения фононов. Результаты расчетов температурной зависимости $l$ в керамике $\mathrm{CaLa}_{2} \mathrm{~S}_{4}$ по формуле (1) представлены на рис. 2 (кривая 3). При проведении расчетов использованы полученные экспериментальные данные теплопроводности керамики $\mathrm{CaLa}_{2} \mathrm{~S}_{4}(\kappa)$. Данные скорости звука $v=5080 \mathrm{~m} / \mathrm{sec}$ керамики $\mathrm{CaLa}_{2} \mathrm{~S}_{4}$ взяты из [7], а значения $C_{V}$ определены (поскольку в литературе нет экспериментальных данных ниже $300 \mathrm{~K}$ ) по интерполяционной формуле Дебая [17]:

$$
C_{V}=3 k\left\{D\left(\frac{\Theta}{T}\right)-\frac{\Theta}{T} D^{\prime}\left(\frac{\Theta}{T}\right)\right\},
$$

где $k-$ постоянная Больцмана; $D-$ функция Дебая; $\Theta$ - температура Дебая. Данные о температуре Дебая $\mathrm{CaLa}_{2} \mathrm{~S}_{4}$ брались из работы [11]. В области температур $300-450 \mathrm{~K}$ значения $C_{V}$, полученные по формуле (2), отличаются от экспериментальных данных, приведенных в [7], не более, чем на 5\%, что позволяет использовать 
формулы (1) и (2) для оценки длины свободного пробега фононов в $\mathrm{CaLa}_{2} \mathrm{~S}_{4}$.

Рассеяние фононов в $\mathrm{CaLa}_{2} \mathrm{~S}_{4}$ в исследованном интервале температур в основном определяется фононфононными и фонон-дефектными процессами взаимодействия. Тогда длину свободного пробега фононов можно представить в виде

$$
l=\left(l_{\mathrm{ph}}^{-1}+l_{d}^{-1}\right)^{-1},
$$

где $l_{\mathrm{ph}}$ - длина свободного пробега фононов, обусловленная фонон-фононными процессами; $l_{d}$ - длина свободного пробега, обусловленная рассеянием фононов на дефектах. Длина свободного пробега при фононфононных процессах в $\mathrm{CaLa}_{2} \mathrm{~S}_{4}$ оценена по формуле [16]:

$$
l_{\mathrm{ph}}=\frac{a}{\beta \gamma T}
$$

где $a^{3}$ - объем, приходящийся на один атом в кристалле; $\beta$ - коэффициент теплового расширения; $\gamma-$ параметр Грюнайзена. Значения $\beta$ и $\gamma$ взяты из $[10,11]$. Результаты расчетов $l_{\mathrm{ph}}$ приведены на рис. 2 (кривая 1 ). Длина свободного пробега фононов, связанная с рассеянием фононов на дефектах, определена из формулы (3) (кривая 2 на рис. 2).

Как видно из рис. 2, в исследованных образцах в ограничении длины свободного пробега фононов при температурах $80-450 \mathrm{~K}$ существенна роль рассеяния фононов на дефектах. Коэффициенты теплопроводности кристалла и керамики $\mathrm{CaLa}_{2} \mathrm{~S}_{4}$ мало отличаются по величине, что свидетельствует о незначительности в ограничении переноса тепла вклада процессов рассеяния фононов на межзеренных границах и дефектах в

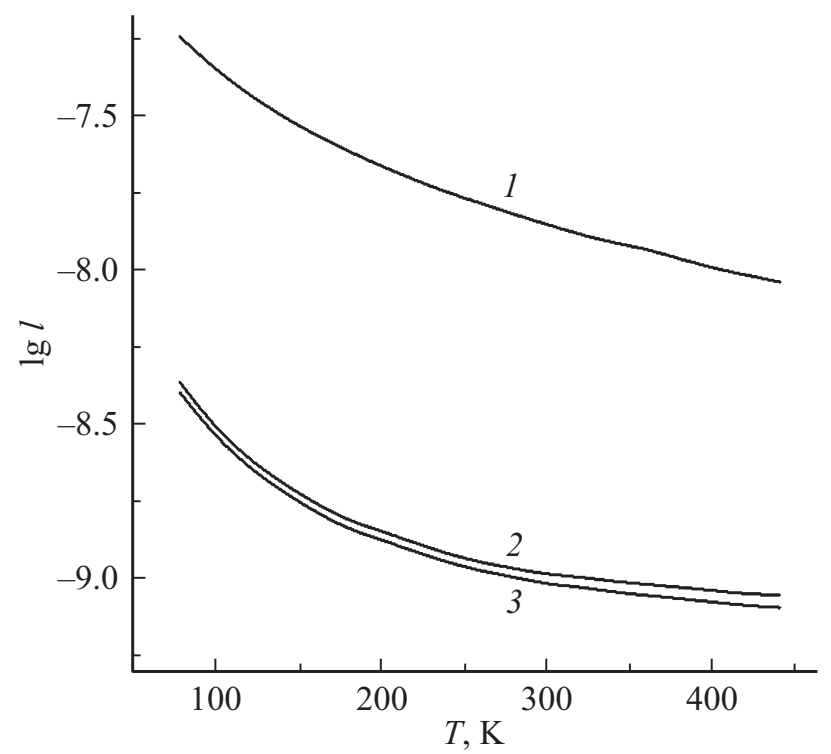

Рис. 2. Температурные зависимости длины свободного пробе-

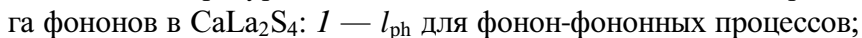
$2-l_{d}$ для фонон-дефектных процессов в керамике; $3-l$, рассчитанная для керамики по формуле (1).

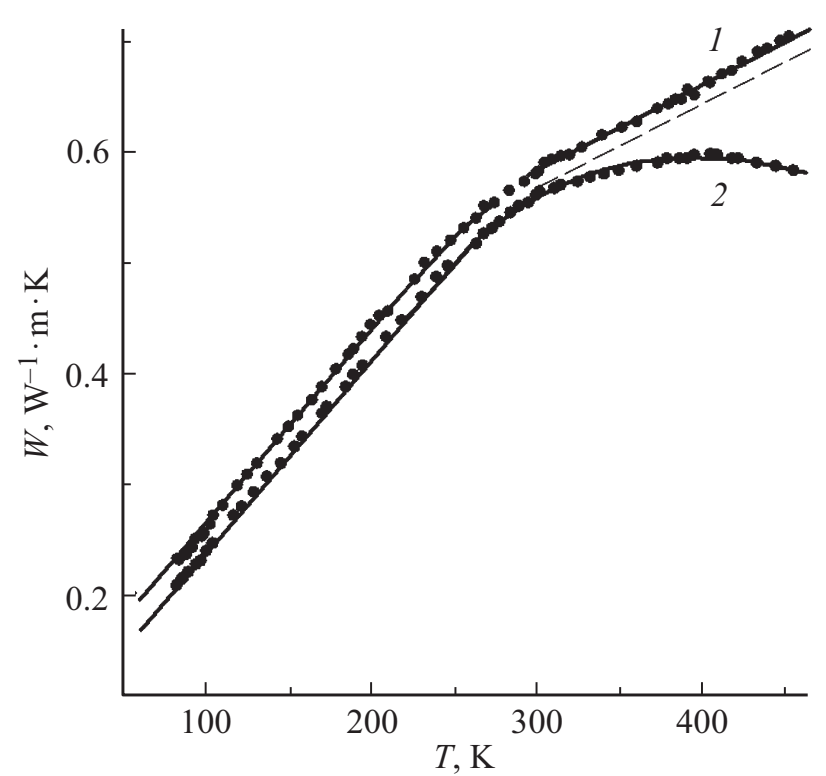

Рис. 3. Температурные зависимости теплового сопротивления $\left(W=\kappa^{-1}\right)$ образцов $\mathrm{CaLa}_{2} \mathrm{~S}_{4}: 1-$ керамика; $2-$ кристалл.

приграничных слоях зерен в керамике. Дефектами, существенно ограничивающими перенос тепла фононами как в кристалле, так и в керамике $\mathrm{CaLa}_{2} \mathrm{~S}_{4}$, являются находящиеся в катионной подрешетке соединения ионы двух типов: $\mathrm{Ca}^{2+}$ и $\mathrm{La}^{3+}$, которые значительно отличаются по массе и упругим параметрам. Это обусловливает сильное рассеяние фононов и снижение их длины свободного пробега. Дополнительное усиление рассеяния фононов на этих ионах происходит и ввиду их неупорядоченного распределения в катионной подрешетке, что подтверждается исследованиями колебательных спектров в кристаллах $\mathrm{CaLa}_{2} \mathrm{~S}_{4}[18]$.

При рассмотрении теплового сопротивления $W=1 / \kappa$ образцов соединения $\mathrm{CaLa}_{2} \mathrm{~S}_{4}$ (рис. 3 ), рассчитанного по экспериментальным данным коэффициента теплопроводности, на температурной зависимости $W$ наблюдаются особенности, для выяснения природы которых проведен анализ составляющих теплопроводности и механизмов ее ограничивающих. Большая ширина запрещенной зоны, оптическая прозрачность обусловливают отсутствие в образцах $\mathrm{CaLa}_{2} \mathrm{~S}_{4}$ электронного механизма переноса тепла. В то же время такие характеристики образцов позволяют предположить возможность участия в теплопереносе электромагнитного излучения (фотонов).

Известно [19], что для кристаллов, в которых основным механизмом переноса тепла являются фононы, температурная зависимость теплового сопротивления имеет вид

$$
W(T)=B T+C,
$$

где $B$ коэффициент, определяющий наклон зависимости $W(T)$, характеризует вещество, и он одинаков для кристалла и керамики. Величина $C$ определяется дефектами в материале. Зависимость $W(T)$ кристалла и керами- 
ки (рис. 3) в области температур $80-240 \mathrm{~K}$ соответствует выражению (5), а при дальнейшем повышении температуры для обоих типов образцов наблюдается отклонение от этой зависимости. При температуре $T>290 \mathrm{~K}$ для керамики снова наблюдается линейная зависимость $W(T)$, но уже с другим значением коэффициента $B$. Область изменения наклона на зависимости $W(T)$ для керамики $\mathrm{CaLa}_{2} \mathrm{~S}_{4}$ находится в интервале $240-290$ К. Следует отметить, что в этой области температур находится характеристическая температура Дебая $\Theta=273 \mathrm{~K}$, определенная по экспериментальным данным коэффициента теплового расширения [11]. Наблюдающаяся особенность, вероятнее всего, определяется фононным спектром $\mathrm{CaLa}_{2} \mathrm{~S}_{4}$ и возбуждением в этой области температур оптических фононных мод, переносящих тепло, что отражается в снижении наклона температурной зависимости $W(T)$ при $T>290 \mathrm{~K}$. В работах $[18,20,21]$ указывается на существование фононных мод, возбуждающихся при температурах 240-290 K. Величина и соотношение масс атомов в элементарной ячейке, наряду с силами взаимодействия ионов в кристалле, определяют фононный спектр соединения и величину энергетической щели между фононными ветвями, а также возможность их участия в теплопереносе. B $\mathrm{CaLa}_{2} \mathrm{~S}_{4}$ соотношение масс атомов $\mathrm{La}$ и $\mathrm{S}$ равно 4.23. Теоретические расчеты показывают [22], что при таком соотношении масс атомов энергетическая щель между акустическими и оптическими ветвями достаточно велика, и ввиду этого вероятность рассеяния переносящих тепло акустических фононов оптическими мала, но при этом возможно участие оптических фононов в теплопереносе. Оптические фононы, возбуждающиеся в $\mathrm{CaLa}_{2} \mathrm{~S}_{4}$ в области температур 240-290 K, могут участвовать в переносе тепла, что приводит к отклонению температурной зависимости теплового сопротивления от линейности при этих температурах. Вклад оптических фононов в теплоперенос приводит к снижению наклона $W(T)$ керамики. В области температур $T>290 \mathrm{~K}$ участие оптических фононов в теплопереносе стабилизируется, и температурная зависимость $W(T)$ снова становится линейной. Аналогичные изменения $W(T)$ наблюдались и на изоструктурных с $\mathrm{CaLa}_{2} \mathrm{~S}_{4}$ образцах сульфида гадолиния $\mathrm{Gd}_{2} \mathrm{~S}_{3}$ [23].

Такая же температурная зависимость теплового сопротивления должна была бы наблюдаться и для кристалла $\mathrm{CaLa}_{2} \mathrm{~S}_{4}$. Однако, в высокотемпературной области, начиная с температуры $300 \mathrm{~K}$, наблюдается заметное отклонение $W(T)$ от линейности (рис. 3, кривая 2). Если считать, что тепловое сопротивление решетки кристалла $\mathrm{CaLa}_{2} \mathrm{~S}_{4}$ в области температур выше $300 \mathrm{~K}$ имеет линейную температурную зависимость с таким же коэффициентом $B$, как и для $W(T)$ керамики в этой области температур, то наблюдаемое отклонение от этой зависимости при $450 \mathrm{~K}$ составляет $\sim 12 \%$. Как уже отмечалось выше, оптическая прозрачность кристалла $\mathrm{CaLa}_{2} \mathrm{~S}_{4}$ в инфракрасной области спектра предполагает возможность участия фотонной составляющей в пере- носе тепла, что может быть причиной наблюдающегося снижения теплового сопротивления.

Проанализируем возможную роль фотонной компоненты в теплопереносе в исследованных образцах $\mathrm{CaLa}_{2} \mathrm{~S}_{4}$. Прозрачность керамических образцов толщиной $3 \mathrm{~mm}$ составляет 70\% [2]. В таких веществах фотонный процесс переноса тепла ограничивается двумя механизмами: поглощением излучения атомами (собственное или внутреннее поглощение данного вещества) и рассеянием на границах кристалла или кристаллитов, из которых он состоит. При этом длина свободного пробега фотонов $L$ определяется формулой

$$
L=\left(l_{\mathrm{abs}}^{-1}+l_{\mathrm{sc}}^{-1}\right)^{-1},
$$

где $l_{\text {abs }}$ - длина свободного пробега фотонов, определяемая внутренним поглощением исследуемого вещества; $l_{\mathrm{sc}}$ - длина свободного пробега, определяемая рассеянием фотонов границами образца или межкристаллитными границами внутри образца. Величина $l_{\text {abs }}$ определяется коэффициентом поглощения данного вещества $\alpha$ : $l_{\mathrm{abs}}=1 / \alpha$, а $l_{\mathrm{sc}}$ равно размеру кристаллита или минимальному размеру образца $d$. В случае крупноблочных образцов или монокристаллов, когда длина свободного пробега фотонов, определяемая внутренним поглощением, мала по сравнению с размерами образца или блоков, из которых он состоит, фотонная теплопроводность определяется выражением $\kappa_{\text {phot }}=\left(16 n^{2} \sigma T^{3}\right) / 3 \alpha$, где $n-$ показатель преломления; $\sigma$ - постоянная Стефана-Больцмана; $\alpha-$ коэффициент поглощения данного вещества для длин волн, соответствующих максимуму излучения при температуре $T$ [24]. Если величина $1 / \alpha$ значительно больше размеров зерен в кристалле или минимального из размеров образца, то [25]:

$$
\kappa_{\text {phot }}=4 n^{2} \sigma T^{3} d \varepsilon,
$$

где $d$ - размер отдельного кристаллика или размер образца; $\varepsilon=(1-R) /(1+R) ; R-$ коэффициент отражения. Коэффициент отражения рассчитывается по известной формуле через коэффициент преломления: $R=(n-1)^{2} /(n+1)^{2}[26]$.

Для $\mathrm{CaLa}_{2} \mathrm{~S}_{4}$ коэффициент поглощения $\alpha=0.1$ [4], следовательно, $l_{\text {abs }}=10 \mathrm{~cm}$, что значительно превосходит размеры зерен в керамике $(4-6 \mu \mathrm{m})$ и наименьший размер измеренных образцов $(2 \mathrm{~mm})$. Длина свободного пробега фотонов в таком случае определяется граничным рассеянием. Показатель преломления $\mathrm{CaLa}_{2} \mathrm{~S}_{4}$ равен 2.53 [26]. Расчеты по формуле (7) при $450 \mathrm{~K}$ для керамики $\mathrm{CaLa}_{2} \mathrm{~S}_{4}$ дают величину $\kappa_{\text {phot }}=4.5 \cdot 10^{-4} \mathrm{~W} / \mathrm{m} \cdot \mathrm{K}$, что составляет $0.03 \%$ от измеренной величины. Вклад фотонной компоненты возрастает с ростом температуры, но ее влияние на теплоперенос в исследованном температурном интервале пренебрежимо мал.

В случае кристалла при 300,350 и $450 \mathrm{~K}$ расчеты по формуле (7) дают значения $\kappa_{\text {phot }}=0.029,0.039$ и $0.18 \mathrm{~W} / \mathrm{m} \cdot \mathrm{K}$, что составляет 3,5 и $11 \%$ соответственно от измеренной величины. Почти такие же отклонения 
от линейной зависимости теплового сопротивления, характерной для фононного теплопереноса, наблюдаются и в эксперименте. Таким образом, результаты проведенного анализа позволяют утверждать, что отклонение от линейности температурной зависимости $W(T)$ в кристалле $\mathrm{CaLa}_{2} \mathrm{~S}_{4}$ при $T \geq 320 \mathrm{~K}$ обусловлено вкладом фотонной компоненты в теплоперенос.

\section{4. Заключение}

На основании проведенных экспериментальных исследований установлено, что на температурной зависимости теплового сопротивления поликристаллов $\mathrm{CaLa}_{2} \mathrm{~S}_{4} \mathrm{c}$ нулевой пористостью, полученных керамической технологией, и образцов, полученных кристаллизацией из расплава, наблюдаются изломы в области температуры Дебая $(273 \mathrm{~K})$. Такое поведение теплового сопротивления, вероятнее всего, обусловлено особенностями фононного спектра и ролью различных фононных ветвей в переносе тепла в этой области температур. В высокотемпературной области измерений снижение теплового сопротивления исследованных образцов $\mathrm{CaLa}_{2} \mathrm{~S}_{4}$ обусловливается участием оптических фононов в теплопереносе. При $T \geq 320 \mathrm{~K}$ в образцах, полученных кристаллизацией из расплава, наблюдается дополнительное снижение теплового сопротивления, что характерно для участия фотонов в переносе тепла. Такой механизм переноса тепла в поликристаллах $\mathrm{CaLa}_{2} \mathrm{~S}_{4}$, полученных керамической технологией в исследованной области температур не наблюдается.

\section{Благодарности}

Авторы благодарят Г.Н. Дронову за предоставленные для исследования образцы.

\section{Конфликт интересов}

Авторы заявляют, что у них нет конфликта интересов.

\section{Список литературы}

[1] P.N. Kumta, S.H. Risbud. J. Mater. Sci. 29, 1135 (1994).

[2] А.В. Кертман. Дис. д-ра хим. наук: 02.00.04; Тюмень. Тюменский гос. ун-т (2010). 342 с.

[3] P. Li, W. Jie, H. Li. J. Am. Ceram. Soc. 94, 1162 (2011).

[4] J.S. McCloy, B.J. Riley, D.A. Pierce, B.R. Johnson, A. Qiao. SPIE Defense, Security, and Sensing International Society for Optics and Photonics (2013). C. 87080N.

[5] B.W. White, D. Chess, C.A. Chess, J.V. Biggers. In: Emerging Optical Materials / Proceedings SPIE. 297 (1981). P. 34.

[6] С.М. Лугуев, Н.В. Лугуева, Т.С. Лугуев. ТВТ 56, 477 (2018).

[7] J.R. Koenig. Final Report to Office of Naval Research Department № SORI-EAS-85-401-5267-IF. Southern Research Inst. Birmingham AL (1985). 78 p.

[8] С.М. Лугуев, Н.В. Лугуева, Ш.М. Исмаилов. Неорган. материалы 38, 423 (2002).
[9] С.М. Лугуев, Н.В. Лугуева, Ш.М. Исмаилов, М.-Р.М. Магомедов. Tp. V Междунар. конф. „Прикладная оптика 2002“. СПб (2002). С. 134.

[10] С.М. Лугуев, Н.В. Лугуева, Ш.М. Исмаилов. ТВТ 42, 704 (2004).

[11] С.М. Лугуев, Н.В. Лугуева, Ш.М. Исмаилов. ФТТ 44, 1023 (2002).

[12] С.М. Лугуев, Н.В. Лугуева, В.В. Соколов. Тр. IX Междунар. конф. „Прикладная оптика - 2010“(18-22 октября 2010) СПб (2010). Т. І. Ч. 2. С. 26.

[13] Ф.К. Волынец, Г.Н. Дронова. В сб.: Тугоплавкие соединения редкоземельных металлов / Под ред. К.Е. Миронова. Наука, Новосибирск (1979). С. 231.

[14] О.В. Андреев, А.В. Кертман, Г.Н. Дронова. В сб.: Физика и химия редкоземельных полупроводников / Под ред. К.Е. Миронова. Наука, Новосибирск (1990). С. 143.

[15] С.М. Лугуев, И.А. Смирнов, Н.В. Лугуева. ГСССД МЭ 218-2014. Стандартинформ, М. (2014). 30 с.

[16] Р. Берман. Теплопроводность твердых тел. Мир, М. (1979). $286 \mathrm{c}$.

[17] Л.Д. Ландау, Е.М. Лифшиц. Статистическая физика. Наука, М. (1964). 567 c.

[18] P.L. Provenzano, S.I. Boldish, W.B. White. Mater. Res. Bull. 12, 939 (1977).

[19] В.С. Оскотский, И.А. Смирнов. Дефекты в кристаллах и теплопроводность. Наука, СПб. (1972). 160 с.

[20] Б.А. Колесов, А.А. Камарзин, В.В. Соколов. ЖСХ 38, 655 (1997).

[21] C.I. Merzbacher, D.L. Chess, W.B. White. Mater. Lett. 64, 334 (2010).

[22] A. Jain, A.I.H. McGaughey. J. Appl. Phys. 116, 073503 (2014).

[23] С.М. Лугуев, Н.В. Лугуева, В.В. Соколов. ФТТ 42, 1013 (2000).

[24] L. Genzel. Z. Physik 135, 177 (1953).

[25] О.А. Сергеев, А.А. Мень. Теплофизические свойства полупрозрачных материалов. Изд-во стандартов, М. (1977). $288 \mathrm{c}$.

[26] S.S. Singh, S. Pratap, J. Prasad, R. Kumar, K. Murari. Def. Sci. J. 48, 173 (1998).

Редактор Т.Н. Василевская 